\title{
Recent Update in The Management of Childhood Nephrotic Syndrome
}

\author{
MIKAYES
}

\begin{abstract}
Summary :
Nephrotic Syndrome (NS) is a common renal disease seen in children. Children who go into complete remission following treatment with corticosteroids are classified as having steroid sensitive NS. In developed countries over $80 \%$ of children with idiopathic NS have steroid sensitive disease. The exact pathogenesis of this condition remains elusive. Podocyte injury and proteinuria are the two main issues in the pathogenesis. Recent studies suggest release of cytokines by T-cells as well as a strong contribution of Bcell immunity. Genetic studies have reported human leucocyte antigen (HLA) class II antigens DR and DQ associations linked to steroid sensitive NS. Most children with steroid sensitive NS have multiple relapses and a significant percentage also develop steroid dependent NS. Diuretic-resistant edema also a clinical problem to manage
\end{abstract}

Introduction:

Nephrotic Syndrome (NS) is a common renal disease seen in children. Children who go into complete remission following treatment with corticosteroids are classified as having "steroid sensitive" NS. In developed countries over $80 \%$ of children with idiopathic NS have steroid sensitive disease ${ }^{1}$. The nephrotic syndrome is characterized by heavy proteinuria ( $>40 \mathrm{mg} / \mathrm{h} / \mathrm{m}^{2}$ or protein/creatinine ratio $>200 \mathrm{mg} / \mathrm{mmol}$ ); hypoalbuminemia $(<25 \mathrm{~g} / \mathrm{L})$; generalized edema ${ }^{2}$ and hypercholesterolemia are almost always present ${ }^{3}$. It should be noted that this definition is distinct from a nephritic 'syndrome' (i.e. glomerulonephritis), which is defined by glomerular hematuria +/- hypertension. It is possible for a patient to be nephrotic, nephritic or nephrotic/nephritic depending on the underlying cause $^{2}$.The incidence of all forms of nephrotic syndrome in childhood is 2-4 per 100000 population, whereas in

Address of Correspondence: Dr. Mohammad Imrul Kayes, Associate Professor, Department of Pediatric Nephrology, Chittagong Medical College \& Hospital, Chittagong, Bangladesh, Mobile: 01819177457, Email: imrulkayes@yahoo.com

Received: 11 June, 2015

Accepted: 7 September, 2015 these patients. These children receive multiple courses of steroids and are at high risk of developing steroid toxicity. Patient with frequent relapses who develop steroid dependency thus require alternative treatment. Steroid resistant NS considers when failure to response within 8 weeks of steroid therapy. Steroids sparing agents used include levamisole, cyclophosphamide, mycophenolate mofetil (MMF), calcineurin inhibitors (cyclosporine and tacrolimus), rituximab and vincristine; these agents have greatly reduced the adverse effects seen with long-term use of steroids; so therapy needs to be individualized to achieve optimal care of each child.

Keywords: Nephrotic Syndrome( NS), Relapse ,Steroid sensitive, Steroid dependency, Steroid sparing agents.

(J Banagladesh Coll Phys Surg 2016; 34: 26-32)

the Indian subcontinent it is estimated at 9-10 per 100000 population $^{3}$, but this figure will vary according to the ethnic mix of the population. For instance, the incidence amongst Asian children in two cities in the UK was reported to range from 9 to 16 per 100000, respectively ${ }^{4}$. Most children (90\%) with nephrotic syndrome have a form of the idiopathic nephrotic syndrome. Causes of idiopathic nephrotic syndrome include minimal change disease (85\%), mesangial proliferation (5\%), and focal segmental glomerulosclerosis (10\%). The remaining $10 \%$ of children have secondary nephrotic syndrome related to systemic or glomerular diseases such as membranous nephropathy or membranoproliferative glomerulonephritis ${ }^{5}$. The predominant pathology is minimal change disease (MCD), with contributions from other pathologies such as focal segmental glomerulosclerosis (FSGS) and mesangial proliferation. This applies only in Caucasian populations, as around the world the pathology varies. For instance, in Africa it has long been thought that 'tropical nephropathy' (malaria, HIV, hepatitis B etc.) predominates, though this has been challenged ${ }^{6}$ with schistosomiasis being responsible for the majority of the cases in South America. Nephrotic 
syndrome could be subdivided into congenital, idiopathic (primary) or secondary ${ }^{3}$.

In general, secondary nephrotic syndrome should be suspected in patients with age $>8 \mathrm{yr}$, hypertension, hematuria, renal dysfunction, extrarenal symptomatology (rash, arthralgias, etc.), or depressed serum complement levels. In certain areas of the world, malaria and schistosomiasis are the leading causes of nephrotic syndrome. Henoch- Schönlein purpura nephritis, lupus nephritis, acute post-streptococcal nephritis, sickle-cell disease, and amyloidosis also may be the cause of nephrotic syndrome. Other infectious agents associated with nephrotic syndrome include hepatitis B virus, hepatitis C virus, filaria, leprosy, and HIV. Nephrotic syndrome has also developed during therapy with numerous drugs and chemicals. The histologic picture may resemble membranous glomerulopathy (penicillamine, captopril, gold, nonsteroidal anti-inflammatory drugs, mercury compounds), minimal change disease (probenecid, ethosuximide, methimazole, lithium), or proliferative glomerulonephritis (procainamide, chlorpropamide, phenytoin, trimethadione, paramethadione $)^{7-11}$.

\section{Idiopathic nephrotic syndrome}

Minimal change disease accounts for most of the cases presenting in childhood. The other histological types of mesangial proliferative and FSGS may well represent the spectrum of a single disorder with varying histological features. The cause of minimal change nephrotic syndrome (MCNS) remains unknown. It is more prevalent in families with an atopic history, and some studies have suggested an abnormality of $\mathrm{T}$ cell function. Although broad-spectrum immunosuppressive drugs have been used to control the disease, there is lack of evidence for classical mechanisms of immunological injury. In minimal change disease, the glomeruli appear normal or show a minimal increase in mesangial cells and matrix. The immunofluorescence studies are negative, and electron microscopy reveals gross podocyte foot process fusion, which is a nonspecific finding in any patient with heavy proteinuria ${ }^{2}$.

\section{Clinical presentations}

Minimal change nephrotic syndrome is more common in boys than girls (2:1) and usually occurs between the ages of 2 and 6 years $^{3}$. There may be an antecedent history of an upper respiratory tract infection and, certainly, these are well known to precipitate relapses in this condition. The presenting feature is usually edema, which is first noticed around the eyes. The edema may become generalized, with swollen limbs, ascites and pleural effusions with diminishing urine output. There may be lethargy, poor appetite, mild diarrhea and, sometimes, abdominal pain ${ }^{2}$. Hematuria (mostly microscopic), hypertension and raised blood urea levels are occasionally observed ${ }^{3}$.

\section{Dignosis}

The diagnosis is suggested by simple urinalysis, which will show heavy proteinuria (3-4 +) by heat test or dipstick test. Measurement of 24 hour urinary protein is not essential. Careful and repeated microscopic urine examination should be done for red cell, persistent microscopic hematuria suggest the likelihood of significant histologic lesion ${ }^{3}$. About $30 \%$ of patients will have transient microscopic hematuria, but gross hematuria is rare. Heavy proteinuria can be confirmed by early morning urine protein/creatinine ratio ( $>200$ $\mathrm{mg} / \mathrm{mmol}$ ). Renal function is usually normal, but there will be a low serum albumin $(<25 \mathrm{~g} / \mathrm{L})$, with raised serum cholesterol (>250 mg/dl) and triglyceride levels. Swabs should be taken from the throat and any skin lesions, as well as a urine culture. An X-ray of chest and Mantoux test should be done. Overt or covert infection can be the cause of steroid resistance. Serological tests such as complement (C3) studies, an ASO titer, hepatitis B surface antigen and antinuclear factor antibodies need only be measured in patients when there is a mixed nephritic/nephrotic picture. Children between the ages of 1 and 10 years are very likely to have steroidresponsive minimal change disease and so prednisolone therapy is usually initiated without a renal biopsy.

A biopsy may be considered in children with nephrotic syndrome if ${ }^{2}$ :

1. onset of NS occurs between 6 and 12 months of age,

2. onset over 12 years of age (other pathology may be more likely),

3. persistent hypertension, microscopic hematuria, or low plasma C3,

4. renal failure - persistent and not attributable to hypovolemia; Secondary nephrotic syndrome and steroid resistance cases require renal biopsy ${ }^{3}$. 


\section{Complications}

The major complication is infection. Spontaneous bacterial peritonitis is the most frequent type of infection. Although Streptococcus pneumoniae is the most common organism casuing peritonitis, gram-negative bacteria such as Escherichia Coli may also be encountered. Other infections such as sepsis, pneumonia, cellulitis and urinary tract infections may also be seen ${ }^{12}$. A high prevalence of tuberculosis has been reported in chidren with nephrotic syndrome ,especially those receiving immunosuppressive drugs for prolong period ${ }^{3}$.The reasons for the susceptibility may be multifactorial and include decreased immunoglobulin levels, ascitic fluid acting as culture medium and immunosuppressive therapy. While on corticosteroids the clinical findings may be masked, and so any child with nephrotic syndrome and abdominal pain should be carefully evaluated. Nephrotic children also have a tendency to arterial and venous thrombosis. The nephrotic syndrome is a hypercoagulable state with high levels of fibrinogen, factor VIII:R:AG and alpha-2macroglobulin with a decrease of both functional and immunological antithrombin III ${ }^{13}$.

\section{Treatment:}

Hospitalization should only be required for the initial attack, when the diagnosis can be established, treatment initiated and the response evaluated. It will also give an opportunity to educate the patient and the family in what may be a frustrating chronic illness. Good education and efficient communication should enable further problems to be assessed and treated on an outpatient basis. Bed rest does not need to be enforced, as the child will determine their appropriate activity level. The traditional high-protein, no-salt-intake diet should be abandoned in favor of trying to maintain the recommended daily allowances of calories and protein in a child whose appetite is likely to be markedly diminished until on steroids ${ }^{14}$.

\section{Edema}

When edema is present, no-added-salt diet is advised, with avoidance of foods known to be high in sodium, particularly snack or processed foods . In severe edema, in addition to sodium restriction, fluid restriction may be necessary ${ }^{15}$. The water intake may be limited to replacement of insensible losses plus urine output minus a planned weight loss ${ }^{3}$. Patients with nephrotic syndrome are prone to hypovolemia and drastic change in the daily weight should be avoided. Diuretics should be used with caution in plasma-volume-depleted nephrotic patients, as they may be predisposed to fluid and electrolyte disturbances. Thiazide diuretics have little effect. Cautious use of loop diuretics such as furosemide (frusemide) (1-2 mg/kg/24 h), in combination with an aldosterone antagonist such as spironolactone $0.5-5 \mathrm{mg} / \mathrm{kg} / 24 \mathrm{~h}$ (which may take several days to act), can be used to control the edema, until there is a diuretic response to the corticosteroids. Occasionally, metolazone $(0.2-0.4 \mathrm{mg} / \mathrm{kg} / 24 \mathrm{~h})$, in combination with furosemide (frusemide), may be needed to induce a diuresis, but careful biochemical monitoring is required. If there are signs of hypovolemia, such as abdominal pain (due to a contracted plasma volume), hypertension, oliguria, low urinary sodium excretion $(<10 \mathrm{mmol} / \mathrm{L})$ or evidence of renal insufficiency, then an i.v. 4.5\% albumin infusion (1 g/kg) given over 3-4 h with careful monitoring and followed by furosemide (frusemide) (1-2 mg/kg) may replenish intravascular volume. For diuretic-resistant symptomatic edema, $20 \%$ albumin infusion ( $1 \mathrm{~g} / \mathrm{kg}$ ) can be added if intravascular volume is adequate, to promote loss of peripheral fluid. Albumin infusions are both expensive and potentially hazardous, as pulmonary edema could be precipitated if the volume status has been misjudged. Since most of the infused albumin is rapidly lost in the urine, there is little place for their routine use. Mannitol ( $5 \mathrm{ml} / \mathrm{kg}$ of $20 \%$ solution) and furosemide (frusemide) ( $2 \mathrm{mg} / \mathrm{kg} /$ dose) have also been used to treat diuretic- resistant edema ${ }^{16}$. 'Resistant oedema' was considered based on failure to achieve therapeutic response to diuretics or a weight loss of $<1 \%$ body weight daily. In a study ${ }^{17}$ reported that response to mannitol-furosemide (intravenous mannitol $0.5-1 \mathrm{gm} / \mathrm{kg} /$ day in single daily dose over $1-2 \mathrm{hrs}$ followed by intravenous furosemide $1 \mathrm{mg} / \mathrm{kg} /$ day for 5 days) combination is as effective as albumin with furosemide in the treatment of diuretic resistant oedema in children with nephrotic syndrome. However, new combination is less costly and may be more useful in developing country like Bangladesh.

Corticosteroid therapy 95\% will respond to steroid therapy within the first 4 weeks. The consensus regimen proposed by the British Association for Paediatric Nephrology was prednisolone $60 \mathrm{mg} / \mathrm{m}^{2} / \mathrm{d}$ until the urine was protein-free for $3 \mathrm{~d}$, followed by $40 \mathrm{mg} / \mathrm{m}^{2}$ for 4 
weeks ${ }^{18}$. Daily prednisolone $60 \mathrm{mg} / \mathrm{m}^{2}$ for a full 4 weeks followed by a further 4 weeks of alternate day therapy at $40 \mathrm{mg} / \mathrm{m}^{2}$ proposed by ISKDC(International Study of Kidney Diseases in Children) is not recommended ${ }^{3}$. The increase in the initial steroid dose acknowledges the evidence that the relapse rate is reduced with increased duration of initial therapy ${ }^{19}$. Now the intial episode is treated with prednisolone $60 \mathrm{mg} / \mathrm{m}^{2} /$ day in 23 divided doses for 6 weeks followed by $40 \mathrm{mg} / \mathrm{m}^{2}$ on alternate days as a single morning dose for 6 more weeks, after which it is discontinued ${ }^{3,15}$. Children in their first episode should be treated for at least three months therapy recommended by Hodson et $\mathrm{al}^{20}$. Cessation of prednisone after 12 weeks without a taper has no disadvantage and may limit the negative effects of prolonged courses of prednisone. A 24- month sustained remission rate of $49 \%$ and frequent-relapse rate of $29 \%$ is expected with this regimen ${ }^{15}$. Nephrologists remain concerned about the possibility of steroid side-effects, with this large initial dosage, and their effect on the hypothalamic pituitary axis. Surprisingly, there is usually little gastric upset from the use of soluble prednisolone in children, and the more expensive enteric coated forms or drugs to control gastric acidity are not routinely prescribed $^{21}$. Children who have problems with vomiting or diarrhea should receive i.v. methylprednisolone in an equivalent dose to the oral prednisolone dosage and additional care should be taken to monitor blood pressure. It is important to exclude occult infection such as urinary tract infection as a cause of steroid resistance. The parents should be told daily steroids may well alter the child's behavior as well as increasing the appetite. General dietary advice about avoiding excess consumption of snacks, etc. should be given. A steroid warning card should be issued, and the parents should report if the child is exposed to infections such as measles or chickenpox, while on daily steroids. Immunization using live vaccines should be avoided until the child has been off daily steroids for at least 3 months, but are permissible if the child is on alternateday steroids ( $<0.5 \mathrm{mg} / \mathrm{kg}$ body weight/d).

\section{Relapse}

When there is a relapse of proteinuria (3 consecutive days of heavy proteinuria [+++ or greater]), treatment may be withheld for up to $5 \mathrm{~d}$ (or possibly 10 if variable proteinuria) unless the child becomes edematous. This is because some children will spontaneously remit during this period. If proteinuria persists, then remission is induced with daily steroids as before until the urine is protein free for $3 \mathrm{~d}$, and then alternate-day corticosteroids are continued for $28 \mathrm{~d}$. More than $75 \%$ of children with minimal change nephrotic syndrome will have at least one relapse.

\section{Frequent relapses or steroid dependency}

If the child has two or more relapses within 6 months of initial treatment, or four or more relapses within any 12month period (frequent relapser), then a slow weaning dose of alternate-day prednisolone may be considered, after inducing remission with daily steroids as mentioned earlier. The prednisolone may be weaned off over 6 months, and by this means steroid toxicity may be minimized.

Steroid dependency may be defined as those who relapse on two consecutive occasions as prednisolone is being decreased, or within 2 weeks of it being discontinued. If a child requires more than $0.5 \mathrm{mg} / \mathrm{kg}$ of prednisolone on alternate days to remain protein free, and particularly if there are signs of steroid toxicity, then alternative therapy should be considered. Such steroid side-effects would include stunting of growth, cataracts, obesity and behavioral changes, but alternative therapy to corticosteroids and/or the advice of a pediatric nephrologist or pediatrician will, preferably, have been sought before many of these side-effects are manifest. Alternative therapy consists of levamisole, cyclophosphamide, chlorambucil and cyclosporine which all reduce the risk of relapse in children with relapsing steroid-sensitive nephritis compared with prednisolone alone ${ }^{22}$. Steroids sparing agents used include levamisole, cyclophosphamide, mycophenolate mofetil (MMF), calcineurin inhibitors (cyclosporine and tacrolimus), rituximab and vincristine.Time to first remission is a strong predictor of the need for these agents $^{23}$. The steroid-sparing effects of these agents have greatly reduced the adverse effects seen with longterm use of steroids. Despite the wide arsenal of agents available, therapy needs to be individualised to achieve optimal care of each child ${ }^{1}$.

\section{Levamisole}

It is an immunomodulatory agent, has been successfully employed in patients with frequent relapse (FR) and steroid dependent (SD) nephrotic syndrome. A dose of $2-2.5 \mathrm{mg} / \mathrm{kg}$ given on alternate days for $1-2$ years or 
longer is effective in 50-60 percent cases. Initially predisolone 0.75 to $1 \mathrm{mg} / \mathrm{kg}$ is given along with levamisole. In 20-30 percent cases predinisolone can be graudually stopped and levamisole alone is sufficient. Side effects of levamisole are infrequent and mild gastrointestinal upset may occur ${ }^{3}$.

\section{Cyclophosphamide}

Steroid-dependent patients, frequent relapsers, and steroid- resistant patients may be candidates for alternative agents, particularly if the child suffers severe corticosteroid toxicity (cushingoid appearance, hypertension, cataracts, and/or growth failure). Cyclophosphamide has been shown to prolong the duration of remission and to reduce the number of relapses in children with frequently relapsing and steroid-dependent nephrotic syndrome. The potential side effects of the drug (neutropenia, disseminated varicella, hemorrhagic cystitis, alopecia, sterility, and increased risk of future malignancy) should be carefully reviewed with the family before initiating treatment. The dose of cyclophosphamide is $2-3 \mathrm{mg} / \mathrm{kg} / 24 \mathrm{hr}$ given as a single dose, is given after remission has been induced with daily steroids, for a total duration of 8-12 wk . Alternate-day prednisone therapy is continued during the course of cyclophosphamide administration ${ }^{3}$. An additional option for the child with complicated nephrotic syndrome is high-dose pulse methylprednisolone. Methylprednisolone is usually given as a $30-\mathrm{mg} / \mathrm{kg}$ bolus (maximum 1,000 mg), with the first 6 doses given every other day, followed by a tapering regimen for periods up to $18 \mathrm{mo}$. Cyclophosphamide may be added to this regimen in selected patients ${ }^{1}$. It was once customary to perform a renal biopsy on all nephrotic children prior to cyclophosphamide therapy. However, this is probably no longer justifiable if the patient is still steroid responsive.

Cyclosporine: Prolonged administration of cyclosporine (3-6 mg/kg/24 hr) has also been effective in maintaining a prolonged remission in children with nephrotic syndrome and is useful as a steroid- sparing agent. Children must be monitored for side effects, including hypertension, nephrotoxicity, hirsutism, and gingival hyperplasia ${ }^{1}$.

Mycophenolate Mofetil (MMF)This is now being increasing used as an alternate to cyclophosphamide, particular when there are concerns about longterm gonadal toxicity. The major limitation to its use in the developing world is its high cost. The dose is 600-1000 $\mathrm{mg} / \mathrm{m}^{2} /$ day or $20-25 \mathrm{mg} / \mathrm{kg} /$ day in two divided doses for 12-36 months. Prednisone is maintained at a dose of 1$1.5 \mathrm{mg} / \mathrm{kg}$ given on alternate days during treatment and then tapered over 4-6 weeks. Leukopenia is a common side effect and leucocyte counts should be monitored every 1-2 months and treatment stopped if it drops below $4000 / \mathrm{mm}^{1}$.

\section{Cyclosporine and tacrolimus}

This treatment is usually reserved for children who fail treatment with the agents above. Cyclosporine $\mathrm{A}$ is given in a dose of $4-5 \mathrm{mg} / \mathrm{kg} /$ day for $12-24$ months while tacrolimus dose $0.1-0.2 \mathrm{mg} / \mathrm{kg} /$ day. Prednisone is continued using a dose of $1 \mathrm{mg} / \mathrm{kg}$ on alternate days and tapered over 6-9 months once remission is achieved. Both agents have the potential for acute and chronic nephrotoxicity ,so renal function should be monitored closely ${ }^{1}$.

\section{Rituximab}

Its use is reserved for patients with marked steroid dependency who fails to respond to other drugs or in patients with toxicity secondary to other drugs. A significant proportion of patients relapse after rituximab treatment. Most relapses occur simultaneously with the recovery of B-cell lymphocyte counts ${ }^{24}$. Maintenance therapy using mycophenolate mofetil is effective in preventing relapses after treatment with rituximab in many cases $^{25}$.Side effects include infusion related reactions (hypotension, fever and rigors), serious infections, and progressive multifocal leukoencephalopathy ${ }^{26}$.

\section{Vincristine}

There has been one report in 2005 of patients treated with vincristine for steroid dependent NS who were relapsing despite cytotoxic or calcineurin treatment ${ }^{27}$. Vincristine was used in a dose of $1-1.5 \mathrm{mg} / \mathrm{m}^{2}$ that was given weekly for 4 weeks intravenously, followed by monthly courses for 6 months. Adverse effects were minimal. The median sustained remission was 5 months. Another study in 2006 that also showed positive results with the use of vincristine ${ }^{28}$. Future controlled studies are needed to carefully evaluate the role of this drug in $\mathrm{NS}^{1}$. 


\section{Choice of steroid sparing agents in practice:}

Given the more favourable toxicity profile of mycophenolate mofetil compared to other agents; many centres are using this agent as first choice for a steroidsparing agent. In countries where levimasole is available, this is also being increasingly used. Some experts however have suggested the use of cyclophosphamide in patients with frequently relapsing, but not steroid dependent NS, the long-term remission rate is much lower and doses used do not warrant the significant potential toxicity ${ }^{23}$. Cyclosporine, although effective in maintaining remission requires prolonged treatment which increases the risks of nephrotoxicity. Hence its use is mainly restricted to patients that fail to maintain remission after a course of mycophenolate mofetil(MMF) or cyclophosphamide without a significant steroid dose. In a study found that treatment with cyclosporine A and combination of cyclosporin A plus MMF was useful for steroid dependent and for remission induction in steroid resistant cases $^{29 .}$

\section{Vitamin D and Calcium Prophylaxis}

Corticosteroids are known to increase the risk for fractures however; no studies have demonstrated that corticosteroid treatment of steroid senstitive NS increases fracture risk .In a randomized controlled trial comparing vitamin $\mathrm{D}$ and calcium prophylaxis with no prophylaxis, bone mineral density was significantly lower in treated than non-treated patients ${ }^{30}$. Hypercalciuria occurred in both groups. Adequate dietary calcium intake is necessary; most such patients also benefit from vitamins D3 supplements ${ }^{3}$. Recently a systematic review based on randomized controlled trials and observational studies concerning children d"18 years with renal diseases requiring steroids is recommended calcium combined with vitamin $\mathrm{D}$ to prevent bone disease ${ }^{31}$.

\section{Psychosocial support}

It is helpful to provide the family of a child with nephrotic syndrome with an information booklet about the condition, as a great deal of anxiety can result with the clinical course of relapse and remission. In addition, the parents have benefited from attending a local parents' group, where they can discuss and share many of their anxieties $^{32}$. If a nephrotic child has been free of relapses for 5 years, then there is a strong chance of a long-term remission. However, some children may continue to relapse into adult life, and those who develop nephrosis earlier in life are likely to relapse more often ${ }^{33}$.

\section{Conclusion:}

Many children with nephrotic syndrome have frequent relapses or become steroid dependent. The precise etiology and pathogenesis of this disease remains elusive although some progress is being made, particularly regarding its genetic origins, in elucidating its cause. Now highly potent drugs available to treat children with frequent relapses and steroid dependency, remission should be the ultimate goal in the management of this disease. Steroids remain the mainstay of treatment and with the introduction of newer therapeutic agents; the prognosis of this disease has greatly improved. The steroid-sparing effects of these agents have greatly reduced the adverse effects seen with long-term use of steroids.

\section{References:}

1. Bhimma R. Steroid Sensitive Nephrotic Syndrome in Children. J Nephrol Therapeutic 2014; S11:003. doi: 10.4172/2161-0959.S11-003

2. Saleem MA, Tinzard J, Dudley J, Inward C, Coward R , McGraw M. Disorders of the urinary system. In: McIntosh N, Helms P, Smyth R, Logan S, editors. Forfar \& Arneil's Textbook of Pediatrics. $7^{\text {th }}$ edn. UK. Churchill Livingstone ; 2008. 580-583.

3. Bagga A, Srivastava RN. Nephrotic syndrome. In: Srivastava RN, Bagga A, editors. Paediatric Nephrology. $5^{\text {th }}$ edn. India. Jaypee Brothers Medical Publishers Ltd; 2011.195-234.

4. Sharples PM, Poulton J, White RHR. Steroid responsive nephrotic syndrome is more common in Asians. Arch Dis Child 1985; 60:1014-1017.

5. Nephrotic syndrome in children: Prediction of histopathology from clinical and laboratory characteristics at time of diagnosis. A report of the International Study of Kidney Disease in Children. Kidney Int 1978; 13: 159-165.

6. Doe JY, Funk M, Mengel M, et al. Nephrotic syndrome in African children: lack of evidence for 'tropical nephrotic syndrome? Nephrol Dial Transplant 2006; 21: 672-676.

7. Barsoum RS. Schistosomal glomerulopathies. Kidney Int 1993; 44: 1-12.

8. Klotman FE.HIV-associated nephropathy. Kidney Int 1999; 56:1161-76.

9. Radford MG, Holley KE, Grande JP, et al. Reversible membranous nephropathy associated with the use of nonsteroidal anti-inflammatory drugs. JAMA 1996; 276: 466. 
10 . Ronco PM. Paraneoplastic glomerulopathies: New insights into an old entity. Kidney Int 1999; 56:355-77.

11. Sitprija V.Nephropathy in falciparum malaria. Kidney Int 1998; 34:867.

12. Pais $\mathrm{P}$, Avner ED. Idiopathic nephrotic syndrome. In : Kleigman RM, Stanton BF, Schor NF, St. Geme JW, Behrman RE, editors. Nelson Textbook of Pediatrics.19th ed. Philadelphia.W B Saunders company; 2011.1804-06.

13. Hoyer PF, Gonda S, Barthels M, et al. Thromboembolic complications in children with nephrotic syndrome. Acta Pediatr Scand 1986; 75: 804-810..

14. Watson AR, Coleman JE. Dietary management in nephrotic syndrome. Arch Dis Child 1993; 69: 179-180.

15. Gipson DS, Massengill SF, Yao L, Nagaraj S, Smoyer WE, et al. Management of childhood onset nephrotic syndrome. Pediatrics 2009; 124(2): 747-757.

16. Lewis MA, Awan A. Mannitol and frusemide in the treatment of diuretic resistant oedema in nephrotic syndrome. Arch Dis Child 1999; 80: 184-5.

17. Huque SS, Rahman MH, Uddin GM, Jahan S, Begum A, Roy RR, Hossain MM. Albumin and furosemide versus mannitol and furosemide in the treatment of diuretic resistant oedema in childhood nephrotic syndrome. Bangladesh J Child Health 2014; 38 (2): 68-73.

18. Consensus statement on management and audit potential for steroid responsive nephrotic syndrome: report of a workshop by the British Association for Paediatric Nephrology and Research Unit, Royal College of Physicians. Arch Dis Child 1994; 70: 151-7.

19. Bargman JM. Management of minimal lesion glomerulonephritis: evidence-based recommenda tions. Kidney Int 1999; Suppl 70: S3-S16.

20. Hodson EM, Knight JF, Willis NS, Craig JC. Corticosteroid therapy for nephrotic syndrome in children. Cochrane Database Syst Rev. 2005; CD001533.

21. Nanjundswamy HM, Phadke KD. Steroid Sensitive Nephrotic Syndrome. The Indian Journal of Pediatrics 2000; 69: 12 .
22. Durkan AM, Hodson EM, Willis NS, et al. Noncorticosteroid treatment for nephrotic syndrome in children. Cochrane Database Syst Rev 2005; CD002290.

23. Harambat J, Godron A, Ernould S, et al. Prediction of steroid-sparing agent use in childhood idiopathic nephrotic syndrome. Pediatr Nephrol. 2013; 28(4):631-8.

24. Kamei K, Ito S, Nozu K, Fujinaga S, Nakayama M, et al. Single dose of rituximab for refractory steroid-dependent nephrotic syndrome in children. Pediatric nephrology 2009; 24: 1321-1328.

25. Ito S, Kamei K, Ogura M, Sato M, Fujimaru T, et al. Maintenance therapy with mycophenolate mofetil after rituximab in pediatric patients with steroid dependent nephrotic syndrome. Pediatr Nephrol 2011;26:1823-1828.

26. Pradhan M, Furth S. Rituximab in steroid-resistant nephrotic syndrome in children: a (false) glimmer of hope? J Am Soc Nephrol 2012; 23: 975-978.

27. Kausman JY, Yin L, Jones CL, Johnstone L, Powell HR. Vincristine treatment in steroid-dependent nephrotic syndrome. Pediatr Nephrol 2005; 20: 1416-1419.

28. Krishnan RG, Coulthard MG, Moghal NE. Is there a role for vincristine in nephrotic syndrome? Pediatr Nephrol 2006; 21: 597.

29. Hibino S, Uemura O, Nagai T, et al. Three year outcome of childhood idiopathic nephrotic syndrome under a unified immunosuppressive protocol. Pediatr Int. 2015; 57(1):85-91.

30. Bak M, Serdaroglu E, Guclu R. Prophylactic calcium and vitamin $\mathrm{D}$ treatments in steroid-treated children with nephrotic syndrome. Pediatr Nephrol 2006;21: 350-354.

31. Gruppen MP, Davin JC, Oosterveld MJ, et al. Prevention of steroid-induced low bone mineral density in children with renal diseases: a systematic review. Nephrol. Dial. Transplant. 2013; doi:10.1093/ndt/gft090

32. Moore EA, Collier J, Evans JHC, et al. Information needs of parents of children with nephrotic syndrome. Child Health 1994; 2:147-149.

33. Lewis MA, Baildom EM, Davis N, et al. Nephrotic syndrome: from toddlers to twenties. Lancet 1989; 255-259. 